\title{
THERMAL ANALYSIS OF PURE AND MULTISUBSTITUTED HYDROXYAPATITE PASTES
}

\author{
EDIT FORIZS ${ }^{a}$, FIRUTA GOGA ${ }^{a}$, ALEXANDRA AVRAMa, $^{a}$ \\ AURORA MOCANU ${ }^{\mathrm{a}, *}$, IOAN PETEANa, OSSI HOROVITZa, \\ MARIA TOMOAIA-COTISEL ${ }^{a, b}$
}

\begin{abstract}
The thermal stability over time of the pure and multisubstituted hydroxyapatite (HAP) pastes, doped with magnesium, silicon, strontium and zinc, synthesized using aqueous precipitation method were investigated by thermal analyses (TG-DTA). Results show high thermal stability of pure and multidoped hydroxyapatite pastes, up to $1000^{\circ} \mathrm{C}$ and even after ageing for 1 year, making these pastes promising nano materials for medical applications.
\end{abstract}

Keywords: hydroxyapatite, doped hydroxyapatites, paste, thermal analysis

\section{INTRODUCTION}

The hydroxyapatite, $\mathrm{Ca}_{10}\left(\mathrm{PO}_{4}\right)_{6}(\mathrm{OH})_{2}$ (HAP), composition is similar to bone, has good biocompatibility and bioactivity therefore is increasingly used in medicine, especially in repairing bone defects as bone grafts, coating material for metallic implants, dental implants, and drug delivery systems [1-3]. Nanocrystalline HAP paste is suitable bone substitute in dental and orthopedic surgery for filling bone defects in minimally invasive surgery. HAP pastes have various applications: as tooth pastes for remineralising and repairing of teeth enamel, for the fabrication of 3D printed bioactive ceramic scaffolds [2, 4].

The biological properties of HAP based materials can be improved by the incorporation of divalent essential metal ions. The effect of silicon [5, 6], magnesium [7, 8], strontium [9, 10], manganese [11] and zinc [11-13] as doping elements on characteristics of hydroxyapatite with potential biomedical applications has been studied extensively $[1,2,11]$.

\footnotetext{
a Babeş-Bolyai University, Faculty of Chemistry and Chemical Engineering, 11 Arany János str., RO-400028, Cluj-Napoca, Romania

b Academy of Romanian Scientists, 54 Splaiul Independentei, RO-050094 Bucharest, Romania

*Corresponding author amocanu@chem.ubbcluj.ro
} 
Multidoped hydroxyapatites with improved properties are more suitable for biomedical application, thus many recent studies have focused on simultaneous doping of hydroxyapatite with copper, zinc and carbonate ions [14]; manganese and strontium [15], strontium and copper [16] and magnesium, zinc and silicon [17, 18]. Hydroxyapatite co-doped with strontium and magnesium, strontium and zinc, magnesium and zinc [19] and simultaneously doped with three essential elements $\mathrm{Sr}, \mathrm{Mg}$ and $\mathrm{Mn}$ [20] and $\mathrm{Sr}, \mathrm{Mg}$ and $\mathrm{Zn} \mathrm{[21]} \mathrm{were} \mathrm{also} \mathrm{reported.}$

Continuing our interest in the field of bioactive materials [22-26] we present here some results concerning thermal stability of three HAP pastes simultaneously doped with essential elements magnesium, strontium, silicon and zinc, with previously described compositions [27]. Water content of pastes was determined by thermal analysis. The thermal stability of the pastes was monitored for one year, namely thermal analyses were performed after 4 months and one year from their preparation.

\section{RESULTS AND DISCUSSION}

Thermal stability over time, of four hydroxyapatite pastes, with previously reported composition [27] were investigated, namely pure hydroxyapatite (HAP, 1) and doped HAP pastes, containing Mg $1.5 \mathrm{wt} \%$, Zn $0.2 \mathrm{wt} \%$ and $\mathrm{Si}$ $0.2 \mathrm{wt} \%$ (2); Mg $1.5 \mathrm{wt} \%$, Zn $0.2 \mathrm{wt} \%$, Si $0.2 \mathrm{wt} \%$ and Sr $5 \mathrm{wt} \%$ (3) and $\mathrm{Mg}$ $1.5 \mathrm{wt} \%$, Zn $0.2 \mathrm{wt} \%$, Si $0.2 \mathrm{wt} \%$ and Sr $10 \mathrm{wt} \%$ (4). The pure and doped pastes kept under storage conditions for 4 months, respectively 1 year, at room temperature in well-closed conditions, were heated in air with the rate of $10{ }^{\circ} \mathrm{C} / \mathrm{min}$ from the room temperature up to $1000{ }^{\circ} \mathrm{C}$. Thermogravimetric data are presented in Table 1 and in Figures 1 and 2.

Table 1. Thermogravimetric data of pure and doped HAP pastes, after 4 months

\begin{tabular}{lll}
\hline \multicolumn{1}{c}{ Paste } & Temperature $\left({ }^{\circ} \mathrm{C}\right)$ & Weight loss $(\%)$ \\
\hline 1. & $30-160$ & 65.96 \\
HAP & $160-1000$ & 1.19 \\
& $\mathbf{3 0 - 1 0 0 0}$ & $\mathbf{6 7 . 1 5}$ \\
\hline 2. & $30-162$ & 71.08 \\
HAP 1.5\%Mg, 0.2\%Si, 0.2\%Zn & $162-1000$ & 1.68 \\
& $\mathbf{3 0 - 1 0 0 0}$ & $\mathbf{7 2 . 7 6}$ \\
\hline 3. & $30-163$ & 64.11 \\
HAP 1.5\%Mg, 0.2\%Si, 0.2\%Zn, 5\%Sr & $163-1000$ & 1.67 \\
& $\mathbf{3 0 - 1 0 0 0}$ & $\mathbf{6 5 . 7 8}$ \\
\hline 4. & $30-150$ & 53.22 \\
HAP 1.5\%Mg, 0.2\%Si, 0.2\%Zn, 10\%Sr & $150-1000$ & 1.93 \\
& $\mathbf{3 0 - 1 0 0 0}$ & $\mathbf{5 5 . 1 5}$ \\
\hline
\end{tabular}




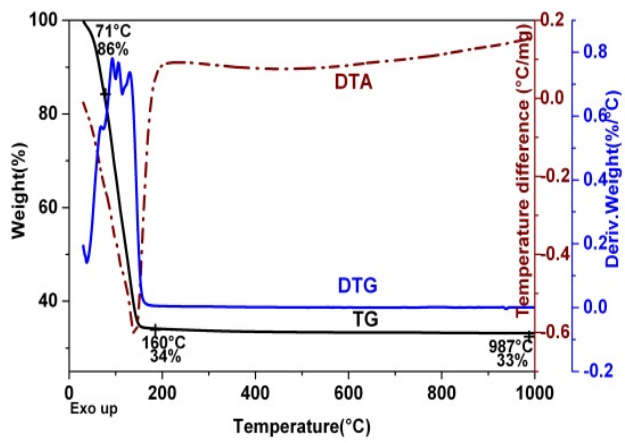

1

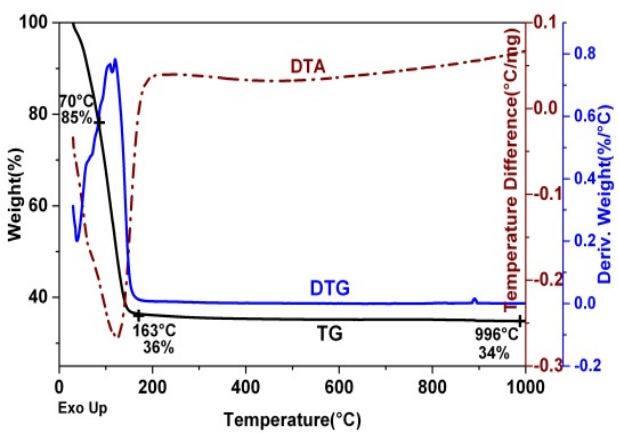

3

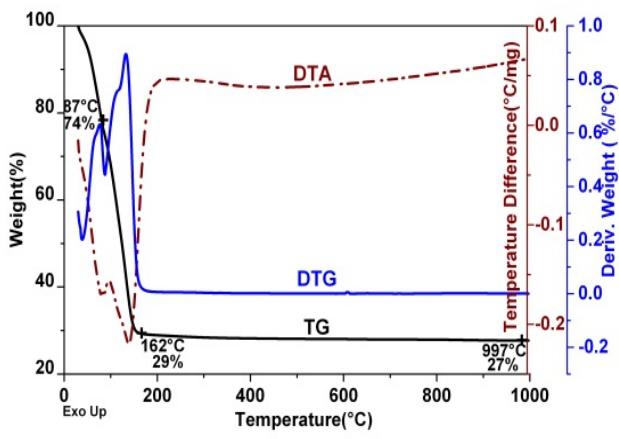

2

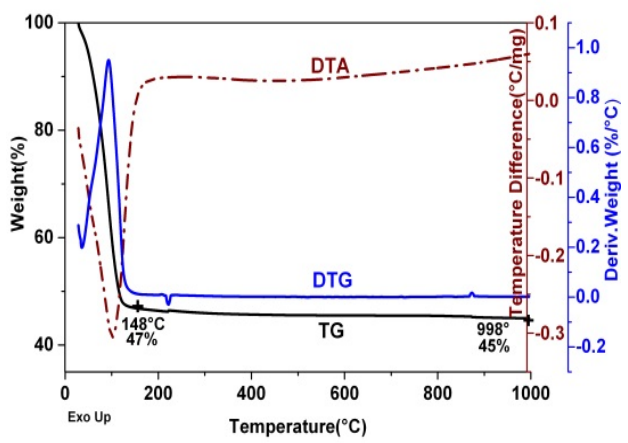

4

Figure 1. Thermal curves of the four pastes: 1) pure HAP (sample 1); 2) HAP $1.5 \% \mathrm{Mg}, 0.2 \% \mathrm{Si}, 0.2 \% \mathrm{Zn}$ (sample 2); 3) HAP 1.5\%Mg, $0.2 \% \mathrm{Si}, 0.2 \% \mathrm{Zn}, 5 \% \mathrm{Sr}$ (sample 3); 4) HAP 1.5\%Mg, 0.2\%Si, 0.2\%Zn, 10\%Sr (sample 4), after 4 months.

Thermal analysis shows that the thermal curves (TG, DTA) of the pure and the doped HAP pastes have the same shape in the range of $30-1000{ }^{\circ} \mathrm{C}$. After 4 months no significant differences were observed in thermal behavior. The only differences refer to the moisture content of the sample. Thermogravimetric monitoring of weight loss shows that weight of all samples decreases continuously with increasing temperature. The highest weight loss occurs in the range $30-200{ }^{\circ} \mathrm{C}$ and can be attributed to very high water content of pastes, since the water molecules surround the hydroxyapatite particles. The corresponding DTA data indicate an endothermic transformation for all samples at around $160^{\circ} \mathrm{C}$ (Fig. 1 and 3). 


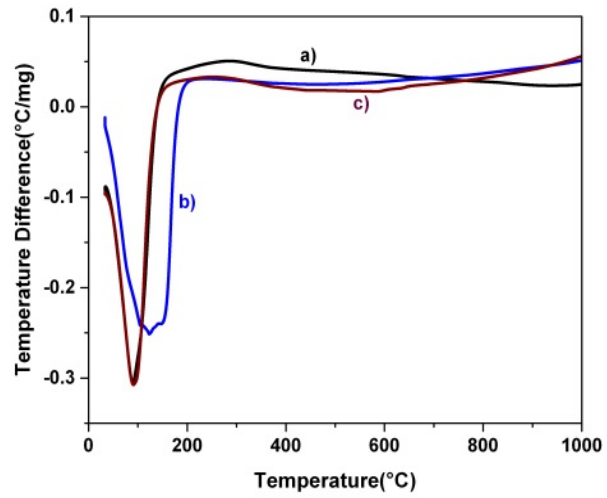

1

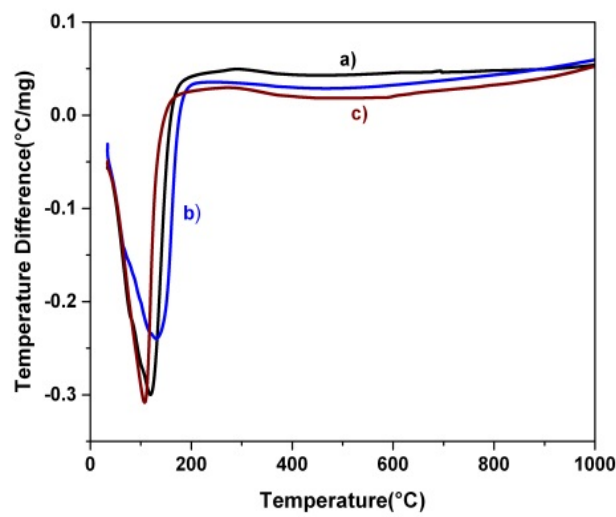

3

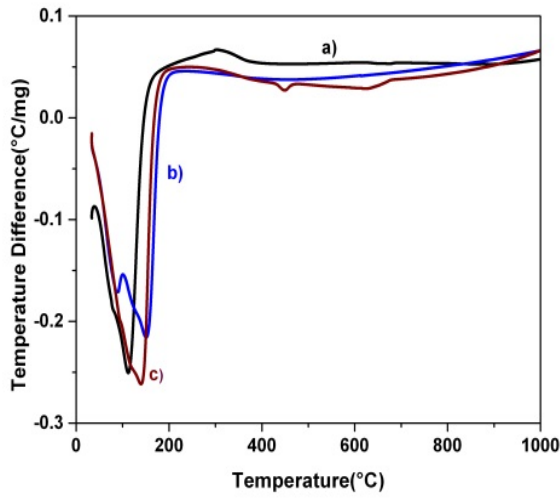

2

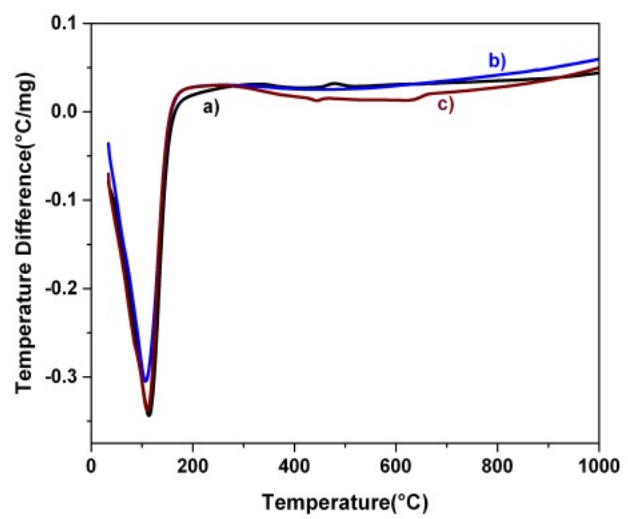

4

Figure 2. Comparative DTA curves for fresh (a), 4 months (b) and 1 year (c) old samples: 1) pure HAP (sample 1); 2) HAP 1.5\%Mg, 0.2\%Si, 0.2\%Zn (sample 2);

3) HAP $1.5 \% \mathrm{Mg}, 0.2 \% \mathrm{Si}, 0.2 \% \mathrm{Zn}, 5 \% \mathrm{Sr}$ (sample 3); 4) HAP 1.5\% Mg, 0.2\%Si, $0.2 \% \mathrm{Zn}, 10 \% \mathrm{Sr}$ (sample 4).

The weight loss in the range $30-200{ }^{\circ} \mathrm{C}$ was $53.5-71.3 \%$; it indicates the removal of moisture and physically adsorbed water, followed in the temperature range of $200-1000{ }^{\circ} \mathrm{C}$ by small gradual weight loss, $1-2 \%$, which can be associated with the removal of chemically adsorbed water on the surface of HAPs particles, in agreement with the literature data [27, 28].

Above $200{ }^{\circ} \mathrm{C}$ the thermogravimetric curves became parallel to each other and up to $1000{ }^{\circ} \mathrm{C}$ (Figure 1 and 3 ) with $\mathrm{x}$-axis. Pure and doped HAP pastes are very stable up to $1000{ }^{\circ} \mathrm{C}$, as found for at least one year aged samples. 


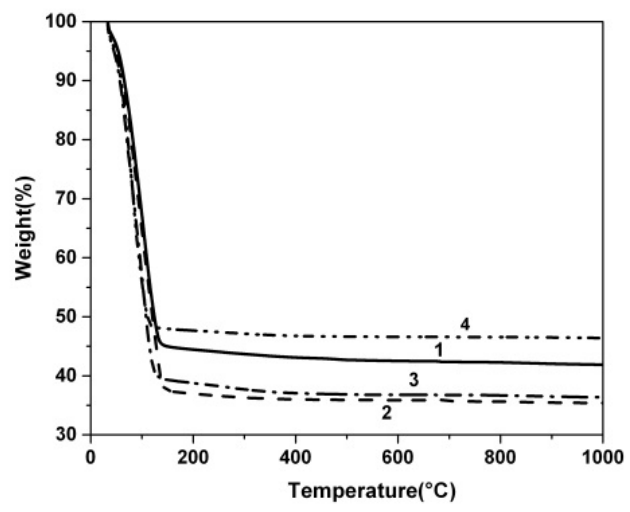

a

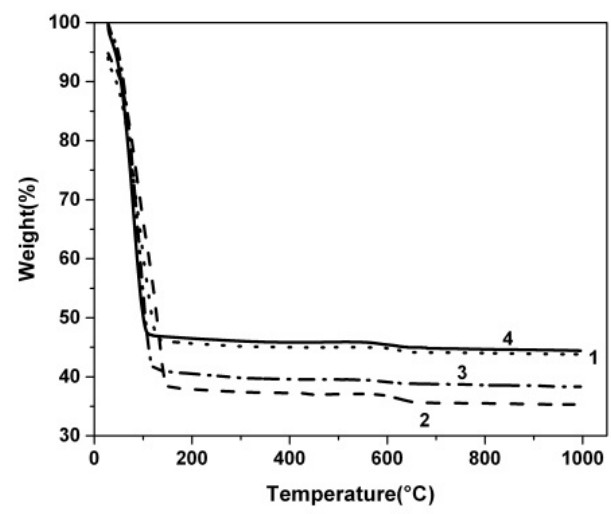

b

Figure 3. TG curves for fresh pastes (a) and 1 year aged (b) pastes: 1) pure HAP (sample 1); 2) HAP $1.5 \% \mathrm{Mg}, 0.2 \% \mathrm{Si}, 0.2 \% \mathrm{Zn}$ (sample 2); 3) HAP $1.5 \% \mathrm{Mg}, 0.2 \% \mathrm{Si}, 0.2 \% \mathrm{Zn}, 5 \% \mathrm{Sr}$ (sample 3); 4) HAP 1.5\%Mg, $0.2 \% \mathrm{Si}, 0.2 \% \mathrm{Zn}, 10 \% \mathrm{Sr}$ (sample 4 ).

The pure and doped hydroxyapatite pastes may contain small content of carbonate, whose decomposition cause insignificant mass loss. The moisture content of these pastes is high but comparable with those found for commercial available pure HAP paste [27].

\section{CONCLUSIONS}

The results of thermal analysis confirm high thermal stability of pure and multidoped hydroxyapatite pastes, up to $1000^{\circ} \mathrm{C}$, even after ageing for 1 year from their preparation. The thermal behavior of pure and doped hydroxyapatite pastes in time shows that this depends mainly on the loss of physically adsorbed and chemically bounded water. The high stability of these ceramic pastes without significant modifications in the structure of pastes makes them appropriately for further use in biomedical applications, as drug delivery systems of antimicrobials and for coating of metallic implants.

\section{EXPERIMENTAL SECTION}

\section{Materials and methods}

The following compounds were used as starting materials: $\mathrm{Ca}\left(\mathrm{NO}_{3}\right)_{2} \cdot 4 \mathrm{H}_{2} \mathrm{O},\left(\mathrm{NH}_{4}\right)_{2} \mathrm{HPO}_{4}, \mathrm{Mg}\left(\mathrm{NO}_{3}\right)_{2} \cdot 6 \mathrm{H}_{2} \mathrm{O}, \mathrm{Zn}\left(\mathrm{NO}_{3}\right)_{2} \cdot 6 \mathrm{H}_{2} \mathrm{O}, \mathrm{Sr}\left(\mathrm{NO}_{3}\right)_{2}$ and tetraethyl orthosilicate $\left(\mathrm{C}_{2} \mathrm{H}_{5} \mathrm{O}\right)_{4} \mathrm{Si}$, (TEOS). Pure HAP and three doped 
hydroxyapatites with the same content of $\mathrm{Mg}, \mathrm{Zn}, \mathrm{Si}$ and different contents in $\mathrm{Sr}$ were obtained by a wet precipitation method, previously reported [6, 10, 13, 26]. All chemicals were reagent grade procured from Merck and Sigma-Aldrich, solutions were prepared with double distilled water, deionized in Elgastat purification system.

\section{Synthesis of pure HAP and doped HAP}

A pure HAP paste was prepared by wet precipitation method, previously described $[6,10,13,26]$; using equal volumes of aqueous $0.25 \mathrm{M} \mathrm{Ca}^{2+}$ solutions and $0.15 \mathrm{M} \mathrm{PO}_{4}{ }^{3-}$ solutions. The $\mathrm{pH}$ of the reaction mixture was fixed at 11.5 using $25 \%$ ammonia solution ( $\mathrm{Ca} / \mathrm{P}$ atomic ratio 1.67$)$. The reaction mixture was stirred $24 \mathrm{~h}$ at $22{ }^{\circ} \mathrm{C}$, and $24 \mathrm{~h}$ at $70{ }^{\circ} \mathrm{C}$. The precipitated solid phase was filtered, washed with distilled water until $\mathrm{pH} 7$. The wet precipitate, considered paste was used as it is.

The doped hydroxyapatites were obtained similarly, with the following modification: the $\mathrm{Ca}^{2+}$ containing solution contains also the doping cations $\left(0.25 \mathrm{M}\right.$ in $\left.\mathrm{Ca}^{2+}+\mathrm{Mg}^{2+}+\mathrm{Zn}^{2+}+\mathrm{Sr}^{2+}\right)$ in calculated amount for the proposed composition of the doped HAP. The anions containing solution $(0.15 \mathrm{M}$ in $\left.\mathrm{PO}_{4}{ }^{3-}+\mathrm{SiO}_{4}{ }^{4-}\right)$ was obtained from $\left(\mathrm{NH}_{4}\right)_{2} \mathrm{HPO}_{4}$, and tetraethyl orthosilicate, TEOS. The $\mathrm{pH}$ was fixed at 11.5 by adding a $25 \%$ ammonia solution. Equal volumes of the two solutions were mixed at $22{ }^{\circ} \mathrm{C}$ keeping the mole ratio $(\mathrm{Ca}+\mathrm{Mg}+\mathrm{Zn}+\mathrm{Sr}) /(\mathrm{P}+\mathrm{Si})$ at the value of 1.67. The obtained pastes were processed in the same way as the pure HAP.

\section{Characterization methods}

Thermal behavior of pure HAP and doped HAP pastes was determined by thermogravimetric analysis (TGA), for the temperature range from $30-1000{ }^{\circ} \mathrm{C}$, using Universal SDTQ600 TA Instruments. Samples were heated in alumina crucibles at a constant heating rate of $10^{\circ} \mathrm{C} / \mathrm{min}$, in flowing air, using simultaneous TG/DTG-DTA/DSC techniques.

\section{ACKNOWLEDGMENTS}

Authors acknowledge the financial support from the Executive Agency for Higher Education, Research, Development and Innovation Funding (UEFISCDI) through grant no. 83 . 


\section{REFERENCES}

1. M. Bayani, S. Torabi, A. Shahnaz, M. Pourali, Biotechnology \& Biotechnological Equipment, 2017, 31(2), 215.

2. N. Eliaz, N. Metoki, Biomaterials, 2017, 10(4), 334.

3. V. Hruschka, S. Tangl, Y. Ryabenkova, P. Heimel, D. Barnewitz, G. Möbus, C. Keibl, J. Ferguson, P. Quadros, C. Miller, R. Goodchold, W. Austin, H. Redl, T. Nau, Scientific Reports, 2017, 7:43425.

4. L. Witek, Y. Shi, J. Smay, Journal of Advanced Ceramics, 2017, 6(2), 157.

5. Z.-Y. Qiu, I.-S. Noh, S.-M. Zhang, Frontiers of Materials Science, 2013, 7(1), 40.

6. Gh. Tomoaia, A. Mocanu, I. Vida-Simiti, N. Jumate, L.-D. Bobos, O. Soritau, M. Tomoaia-Cotisel, Materials Sciences and Engineering C, 2014, 37, 37.

7. D. Laurencin, N. Almora-Barrios, N.H. de Leeuw, C. Gervais, C. Bonhomme, F. Mauri, W. Chrzanowski, J.C. Knowles, R.J. Newport, A. Wong, Z. Gan, M.E. Smith, Biomaterials, 2011, 32, 1826.

8. A. Farzadi, F. Bakhshi, M. Solati-Hashjin, M. Asadi-Eydivand, N.A.A. Osman, Ceramics International, 2014, 40, 6021.

9. C.F. Marques, A. Lemos, S.I. Vieira, O.A.B. da Cruz e Silva, A. Bettencourt, J.M.F. Ferreira, Ceramics International, 2016, 42, 2706.

10. P.T. Frangopol, A. Mocanu, V. Almasan, C. Garbo, R. Balint, G. Borodi, I. Bratu, O. Horovitz, M. Tomoaia-Cotisel, Revue Roumaine de Chimie, 2016, 61(4-5), 337.

11. E. Boanini, M. Gazzano, A. Bigi, Acta Biomaterialia, 2010, 6, 1882.

12. Z.-S. Tao, W.-S. Zhou, X.-W. He, W. Liu, B.-L. Bai, Q. Zhou, Z.-L. Huang, K.K. Tu, H. Li, T. Sun, Y.-X. Lv, W. Cui, L. Yang, Materials Science and Engineering C, 2016, 62, 226.

13. C. Garbo, M.Sindilaru, A. Carlea, Gh. Tomoaia, V. Almasan, I. Petean, A. Mocanu, O. Horovitz, M. Tomoaia-Cotisel, Particulate Science and Technology, 2017, 35(1), 29.

14. O. Livitska, N. Strutynska, I. Zatovsky, I. Nikolenko, N. Slobodyanik, Y. Prylutskyy, M. Epple, O. Prymak, A. Byeda, Mat.-wiss. u. Werkstofftech., 2016, 47(2-3), 85.

15. Y. Huang, H. Qiao, X. Nian, X. Zhang, X. Zhang, G. Song, Z. Xu, H. Zhang, S. Han, Surface and Coating Technology, 2016, 291, 205.

16. Y. Huang, M. Hao, X. Nian, H. Qiao, X. Zhang, X. Zhang, G. Song, J. Guo, X. Pang, H. Zhang, Ceramics International, 2016, 42, 11876.

17. Gh. Tomoaia, M. Tomoaia-Cotisel, L.-B. Pop, A. Pop, O. Horovitz, A. Mocanu, N. Jumate, L.-D. Bobos, Revue Roumaine de Chimie, 2011, 56 (10-11), 1039.

18. Gh. Tomoaia, O. Soritau, M. Tomoaia-Cotisel, L.-B. Pop, A. Pop, A. Mocanu, O. Horovitz, L.-D. Bobos, Powder Technology, 2013, 238, 99.

19. O. Kaygili, S. Keser, Materials Letters, 2015, 141, 161. 
20. M.P. Moreira, G.D. de Almeida Soares, J. Dentzer, K. Anselme, L.A. de Sena, A. Kuznetsov, E.A. dos Santos, Materials Science and Engineering C, 2016, 61, 736.

21. D. Gopi, E. Shinyjoy, L. Kavitha, Ceramics International, 2015, 41, 5454.

22. E. Forizs, A. Debreczeni, A. Patrut, A.-Z. Kun, I.B. Cozar, L. David, I. SilaghiDumitrescu, Revue Roumaine de Chimie, 2010, 55(10), 697.

23. P. Bombicz, J. Madarasz, E. Forizs, M. Czugler, G. Pokol, S. Gal, A. Kalman, Zeitschrift fur Kristallographie, 2000, 215, 317.

24. F. Goga, E. Forizs, A. Avram, A. Rotaru, A. Lucian, I. Petean, A. Mocanu, M. Tomoaia-Cotisel, Revista de Chimie (Bucharest), 2017, 68(6), 1193.

25. O. Horovitz, Gh. Tomoaia, A. Mocanu, T. Yupsanis, M. Tomoaia-Cotisel, Gold Bulletin, 2007, 40(4), 295.

26. G. Furtos, M. Tomoaia-Cotisel, C. Garbo, M. Senila, N. Jumate, I. Vida-Simiti, C. Prejmerean, Particulate Science and Technology, 2013, 31(4), 392.

27. F. Goga, E. Forizs, G. Borodi, Gh. Tomoaia, A. Avram, R. Balint, A. Mocanu, O. Horovitz, M. Tomoaia-Cotisel, Revista de Chimie (Bucharest), 2017, 68(12), in press.

28. Y.Y. Özbek, F.E. Bastan, F. Üstel, Journal of Thermal Analysis and Calorimetry, 2016, 125, 745. 